\title{
Relationship the level of Lise öğrencilerinin internet internet addiction with personality traits of high school students bağımlılık düzeyinin kişilik özellikleriyle ilişkisi
}

\author{
İbrahim Taş ${ }^{1}$ \\ Tuncay Ayas ${ }^{2}$
}

\begin{abstract}
Internet that adds the differences to the lives of the people from day it entered into the life of mankind and will continue to add these differences in the next years, causes the emergence of some negative effects when it is used except its intended purpose. Internet addiction is regarded as one of these drawbacks. This study examines the relationship between internet addiction and personality traits of high school students. Participants consist of 927 students (female $=440,47.5 \%$; male $=487$, $52.5 \%$ ) from various high schools in the provincial center of İstanbul. The ages of the students vary from 14 to 18 and the majority of them are 16 years old. The results of this study, which is realized to analyze the relationship between internet addiction and personal traits, indicate that personality traits such as extraversion and openness were negatively low level related to internet addiction whereas conscientiousness was positively low level associated. When the variables of personality traits are considered as whole, it can be observed that a low level and positive significant relationship $(\mathrm{R}=.22, \mathrm{p}<.01)$ reveals between internet addiction and personality traits.
\end{abstract}

Özet

İnternet insanoğlunun hayatına girdiği günden itibaren insanların hayatına farklilıklar katmış ve bundan sonraki süreçte de katmaya devam edecek gibi görünmektedir. Ancak internetin amac1 dışında kullanılması bireyin günlük hayatını olumsuz şekilde etkileyen bazı aksaklıkların ortaya çıkmasına neden olmaktadır. $\mathrm{Bu}$ olumsuzluklardan biri de internet bağımliliğ1 olarak değerlendirilmektedir. Bu araştırmada lise öğrencilerinin internet bağımllık düzeyinin kişilik özellikleriyle olan ilişkisinin araştırılması amaçlanmıştır. Araştırmanın katılımcıları İstanbul il merkezinde yer alan farklı liselerde öğrenim gören 927 öğrenciden oluşmuştur. Katılımcilarin 440'1 (\%47.5) bayan, 487'si (\%52.5) erkektir. Öğrenciler 14 ile 18 yaşları arasında ve çoğunluğu 16 yaşındadır. İnternet bağımllık düzeyinin kişilik özellikleriyle ilişkisini incelemek amacıyla yapılan bu çalışmada internet bağımllık düzeyinin kişilik özelliklerine göre farklılaştı̆g tespit edilmiştir. İnternet bağımlılık düzeyinin dışadönüklük kişilik özelliğiyle düşük düzeyde negatif ilişkili, özdenetim kişilik özelliği ile düşük düzeyde pozitif ilişkili ve yeniliğe açıklık kişilik özelliği ile düşük düzeyde negatif ilişkili olduğu görülmektedir. Kişilik özellikleri değişkenleri birlikte ele alındığında internet

1Student of Ph.D., Sakarya University, Education Faculty, Department of Educational Sciences, ibrahimtas34@gmail.com

${ }^{2}$ Doç. Dr, Sakarya University, Education Faculty, Department of Educational Sciences, tayas@,sakarya.edu.tr 
Taş, İ. \& Ayas, T. (2015). Lise öğrencilerinin internet bağımlılık düzeyinin kişilik özellikleri ile ilişkisi. International Journal of Human Sciences, 12(2), 150-162. doi:10.14687/ijhs.v12i2.3279

Keywords: Internet Addiction, Personality bağımlılı̆̆ ile pozitif, düşük düzeyde ve anlamlı Traits, High School,Correlation, Regression ilişkili olduğu görülmektedir $(\mathrm{R}=.22, \mathrm{p}<.01)$.

(Extended English abstract is at the end of this Anahtar Kelimeler: İnternet bağımlılığı, Kişilik document)

Özellikleri, Lise, Korelasyon, Regresyon

\section{Giriş}

Kişilik, Latincede tiyatro oyuncularının rollerine uygun olarak yüzlerine taktıkları "maske" anlamına gelen "persona" sözcügüünden türetilmiştir (Köknel, 1982). Kişilik kavramı, bir insanı başkalarından ayıran özelliklerin tümünü, çevreye uyum sağlamak için geliştirdiği davranış kalıplarını ifade eder. Başka bir deyişle kişilik, çekirdekleri yaşamın ilk yıllarında atılan, altıncı yaşta ana çizgileri ortaya çıkan, son halini gençlik çağının sonlarına doğru alan, bireyin örgütlenmiş, kalıplaşmış duygu, tutum ve davranışları bütünüdür. Kişilik aynı zamanda bireyin çevresiyle sürekli olarak girdiği etkileşimin ve uyumun sonucudur (Yörükoğlu, 1986). Kişilik, çevrenin kişiyi nasıl alg1ladığıyla yakından ilişkilidir ve doğrudan gözlenebilir bir yapı değildir. Dolaylı olarak bireyin davranışları gözlemlenerek onun kişiliği hakkında fikir sahibi olunabilir (Haskan, 2013).

Kişilik çok yönlü ve karmaşık bir yapıdır. Zekâ, duygu, irade, heyecan, mizaç, biyolojik yapı, kalıtım, çevre, sosyo-ekonomik etkenler gibi çeşitli etkenleri içinde barındıran bir kavramdır (Altınköprü, 1980). Psikologlar kişiliği “bireysel farklılık” kavramıyla ifade etmektedirler. Onlar bireysel farklılık kavramıyla kişiyi diğerlerinden ayıran özelliklere işaret etmektedirler. Kişilik kavramı üzerinde psikologlar uzlaşamamışlardır. Bununla birlikte bütün yaklaşımların ortak bir ifadesi olarak kişilik, bireyin çevreye uyumunu belirleyen karakteristik (birbiriyle tutarlı) davranış örüntüleri ve düşünce biçimleri olarak tanımlanabilir (Atkinson, Atkinson ve Hilgard, 1995).

Modern dünyada internete erişim ve bilgisayar kullanımı yaygındır. Hayatın her kesiminden insanlar bilgisayarlarını kullanarak veya internete girerek yararlı saatler geçirebilirler (Shaw ve Black, 2008). İnternet son yllarda hem ergenlerde hem de yetişkinlerde en önemli akademik ve eğlence aracı olarak karşımıza çıkmaktadır. İnternet bilgiye ulaşmada, iletişimde ve dünyanın herhangi bir yerindeki diğer insanlara ulaşmada kolay ve anında ulaşım imkânı sağlar (Ko, Yen, Yen, Chen ve Chen, 2012). İnternetin kolaylaştırıcıllı̆ı ve ulaşılabilirliği interneti özellikle üniversite öğrencileri için en popüler eğlence ve akademik etkinlik alanı yapmaktadır (Ko, Yen, Chen ve Chen, 2009). İnternetin düşük maliyetli olması, kapsayıcıllğının giderek artması, daha çok ve daha yüksek kalitede multi medya kaynakları sunması internetin popülaritesini artıran diğer etkenlerdir (Chou, Condron ve Belland, 2005). 
Taş, İ. \& Ayas, T. (2015). Lise öğrencilerinin internet bağımlılık düzeyinin kișilik özellikleri ile ilişkisi. International Journal of Human Sciences, 12(2), 150-162. doi:10.14687/ijhs.v12i2.3279

Gelişen ve sürekli olarak değişen teknoloji beraberinde yeni bağımllıklar getirmiştir (Kalkan ve Kaygusuz, 2013). Bilgi ve iletişim teknolojilerine bağımlılık konusu son birkaç yılda yaygın olarak tartışılmaya başlanmıştır. Yeni teknolojilerin ruh sağlığı üzerindeki etkisi hakkında da bilim literatüründeki çalışmalarda artış vardır. Çünkü teknolojinin uyumsuz kullanımı psikolojik sıkıntı veya bozukluklar yaratabilmektedir (Beranuy, Oberst, Carbonell ve Chamarro, 2009). Teknoloji bağımlılığına ilgi ilk olarak 1990’lı yılların başına kadar gider. Araştırmacılar ilk olarak televizyonun etkisini çalışmışlardır (Kubey ve Csikszenmihalyi, 2002. Akt. Shapira, Lessing, Goldsmith, Szabo, Lazoritz, Gold ve Stein, 2003).

Alan yazın incelendiğinde, internet bağımlılı̆̆ı ile ilişkili farklı değişkenlerin olduğu görülmektedir. $\mathrm{Bu}$ faktörlerden birinin de bireylerin kişilik özellikleri olduğu alan yazın incelemelerinden görülmektedir. Literatürde kişilik ile ilgili çok sayıda çalısma yapılmıştır. Wang, Ho, Chan ve Tse, (2015) tarafindan yapılan çalısmada ergenlerin internet bağımlılı̆̆ına eşlik eden kişilik özellikleri araştırılmıştır. Çalışmada yüksek nörotizm ve düşük özdisiplinin internet bağımlılığına anlamlı şekilde eşlik ettiği görülmüştür. İnternet uygulamaları açısından kişilik özellikleri değerlendirildiğinde düşük özdisiplin ve düşük yeniliğe açıklığın online oyun bağımlılı̆̆ına anlamlı düzeyde eşlik ettiği, nörotizm ve dışadönüklüğün ise anlamlı düzeyde sosyal ağ bağımlılığına eşlik ettiği görülmüştür. Kuss, Shorter, Rooij, Mheen ve Griffiths (2014) tarafindan yapılan bir çalışmada düşük uyumluluk ve yüksek nörotizmin internet bağımlılı̆̆ına eşlik ettiği görülmüsstür. Ayrıca düşük özdisiplin ve düşük güçlülüğün ergenlerde internet bağımlılığının yordayıcısı olduğu görülmüştür. Servidio (2014) tarafından yapılan çalışmada üniversite öğrencilerinde internet bağımlılı̆̆ı, kişilik özellikleri ve çeşitli değişkenler açısından incelenmiştir. Çalışmada uyumluluk ve dışadönüklük internet bağımlılığı ile negatif ilişkili, yeniliğe açıklık ise pozitif ilişkili bulunmuştur. Nörotizm kişilik özelliği ise internet bağımlılı̆̆ı ile ilişkisiz bulunmuştur. Aynı zamanda özdisiplin kişilik özelliğinin internet bağımlılığını yordamadığı görülmüştür. Volmer ve diğerleri (2014) yaptıkları çalışmada dışadönüklerle yumuşak başlıların daha az oyun bağımlısı olduğunu belirlemişlerdir. Taş, Eker ve Anlı (2014) tarafindan yapılan çalışmada lise öğrencilerinde internet bağımlllı̆̆ tespit edilmiştir. Çalışmada internet bağımlılı̆̆ının okul değişkeni ve sınıf değişkenine göre farklılaştığı tespit edilmiştir. İnternet bağımlılı̆̆ının Anadolu Lisesinde ve İmam Hatip Lisesinde, Sağlık Meslek Lisesinden, Endüstri Meslek Lisesinden ve Ticaret Meslek Lisesinden anlamlı düzeyde daha fazla olduğu tespit edilmiştir. Sınıf değişkeni açısındanda internet bağımlılı̆̆ının 11. Sınıf öğrencilerinde 9. ve 10. Sınıf öğrencilerinden daha fazla olduğu tespit edilmiştir.

Chew ve Dillon (2014) tarafindan üniversite öğrencileri ile yapılan bir çalışmada kadınların erkeklerden daha yüksek uyumluluk puanlarının olduğu görülmüştür. Görüşme anksiyetesi, sınav ve 
Taş, İ. \& Ayas, T. (2015). Lise öğrencilerinin internet bağımlılık düzeyinin kişilik özellikleri ile ilişkisi. International Journal of Human Sciences, 12(2), 150-162. doi:10.14687/ijhs.v12i2.3279

sınıf anksiyetesi, yardım isteme korkusu gibi anksiyete durumları ile nörotizm arasında pozitif, deneyime açıklık ve uyumluluk arasında negatif ilişki bulunmuştur. Morsünbül (2014) tarafindan yapılan çalışmada üniversite öğrencilerinde özdisiplin ve dışadönüklük kişilik özelliklerinin internet bağımlılığını olumsuz yönde yordadığı, nörotizm kişilik özelliğinin ise olumlu yönde yordadığı tespit edilmiştir. Landers ve Lounsbury (2006) tarafından yapılan üniversite öğrencilerinin kişilik özellikleri ile internet bağımlllı̆̆ arasındaki ilişkinin incelendiği çalısmada özdisiplin, dışadönüklük ve yumuşak başlılık internet bağımlılığı ile negatif ilişkili bulunmuştur. Ayrıca çalışmada özdisiplin akademik amaç için internet kullanımı ile pozitif ilişkili bulunmuştur. Özkan (2013) tarafından yapılan çalışmada İnternet kullanım amaçlarından tanınma tanıma amaçlı kullanım erkeklerde dışadönüklük ile kadınlarda ise nörotizm ile pozitif ilişkili çıkmıştır. Çalışmada internet bağımlılığı nörotizm kişilik Özelliği ile pozitif ilişkili bulunmuştur. Cao ve Su (2006) tarafinda ergenlerle yapılan çalışmada İnternet bağımlısı grupta nörotizm ve psikotizm kişilik özelliklerinin anlamlı düzeyde yüksek olduğu görülürken, internet bağımlılı̆̆ı ile dışadönüklük ve içe dönüklük kişilik özellikleri arasında anlamlı bir farklılık görülmemiştir.

Hamburger ve Ben-Artzi (2000) tarafindan yapılan çalşmada nörotizm ve dişadönüklük kişlik özelliklerinin farklı internet servislerini kullanmayı yordadığı görülmüştür. Dışadönüklük eğlence servisleri ile ilişkili iken, nörotizm bilgi edinme servisleri ile negatif ilişkili görülmüştür. Cinsiyet değişkeni açısından erkekler için dışadönüklük eğlence servisleri ile pozitif, nörotizm bilgi edinme servisleri ile negatif ilişkili bulunmuştur. Kadın cinsiyeti açısından bakıldığında dışadönük olma ile sosyal servisler arasında negatif ilişki görülürken nörotizm sosyal servislerle pozitif ilişkili bulunmuştur.

Kuss, Griffiths ve Binder, (2013) tarafindan üniversite öğrencileri yapılan bir çalışmada öğrencilerin \% 3.2'si internet bağımlısı çıkmıştır. Kişilik özelliklerinden nörotizmin internet bağımlılığının en güçlü yordayıcısı olduğu görülmüştür. Çalışmada anlamlı ilişki bulunan ikinci kişilik özelliğinin yumuşak başlılık olduğu görülmüştür. İnternet bağımlılarında bu puan bağımlı olmayanlardan önemli ölçüde daha düşük bulunmuştur. Yeniliğe açıklık kişilik özelliği internet bağımlılarında, bağımlı olmayanlardan önemli derecede daha yüksek bulunmuştur. Çalışmada internet bağımlılığını yordayıcı iki temel etken bulunmuştur. Yeniliğe açıklık online oyunu yordarken, nörotizmin önemli ölçüde online alışverişi yordadığı tespit edilmiştir. Kuss ve arkadaşlanı (2013) tarafindan yapılan çalışmada, kişilik özelliklerinden nörotizmin internet bağımlllı̆ıın yordadığı, uyumsuzluğun internet bağımlılı̆̆ını artırdığ1 görülmüştür. Ayrıca beceriklilik ve özdisiplin kişilik özellikleri ile internet bağımlılı̆̆ı arasında pozitif ilişki tespit edilmiştir. Dalbudak ve Evren (2013) tarafindan yapılan çalışma da da dışadönüklük ve yalan puanlarının bağımlı olmayan grupta daha yüksek olduğu tespit edilmiştir. Köse, Çınar ve Akduran (2012) tarafindan yapılan bir çalışmada internet bağımlıllğı ile öz 
Taş, İ. \& Ayas, T. (2015). Lise öğrencilerinin internet bağımllık düzeyinin kişilik özellikleri ile ilişkisi. International Journal of Human Sciences, 12(2), 150-162. doi:10.14687/ijhs.v12i2.3279

disiplin ve uyumluluk kişilik özellikleri arasında negatif ilişki, nörotizm kişilik özelliği ile pozitif ilişki olduğu tespit edilmiştir. Çelik, Atak ve Başal (2012) tarafindan üniversite öğrencileri ile yapılan çalışmada internet bağımlılı̆ı ile özdisiplin, dışadönüklük ve nötotizm kişilik özellikleri arasında negatif, yeniliğe açılık ve uyumluluk kişilik özellikleri arasında pozitif ilişki tespit edilmiştir.

Durak Batıgün ve Kılıç (2011) tarafindan yapılan bir çalışmada üniversite öğrencilerinde internet bağımlılı̆̆ı ile kişilik özellikleri, psikolojik belirtiler ve bazı sosyo-demografik özellikler incelenmiştir. Çalışmada İnternet bağımlllı̆ğ yüksek olan bireylerin interneti gün içerisinde daha uzun süre kullandıkları ve daha çok iletişim amaçlı kullandıkları belirlenmiştir. Kişilik boyutları değişkeni açısından değerlendirildiğinde, internet bağımlılığı düşük olan grubun internet bağımlılı̆̆1 yüksek olan gruba göre özdenetiminin daha yüksek, uyumluluk ve nörotizm puanlarının da anlamlı düzeyde daha düşük olduğu görülmüştür. Psikolojik belirtiler değişkeni açısından değerlendirildiğinde, internet bağımlılı̆̆1 yüksek olan bireylerin tüm belirti alt ölçeklerinden diğer gruba göre anlamlı düzeyde yüksek puanlar aldıkları görülmüştür. Haddadain, Abedin ve Monirpoor (2010) tarafından yapılan, üniversite öğrencilerinin kişilik özellikleri ile romantik ilişkilerinin ele alındığı bir çalışmada kişilik, aile yapısı ve cinsiyetin internet bağımlılı̆̆ üzerindeki etkisinin araştırılmıştır. Çalışmada nörotizm özelliğinin daha çok internette ortaya çıtığı ve bu durumunda internet kullanımını artırdığı görülmüştür. Çalışmada uyumluluk kişilik özelliği ile internet bağımlılığı alt ölçeklerinden ruh hali değişimi, takıntılı olma ve sosyal yarar arasında negatif ilişki görülmüştür. Yeniliğe açılık kişilik özelliği de ruh hali değişimi ve takıntıllılk ile negatif ilişkili bulunmuştur. Ayrıca dışadönüklük ve özdisiplinin problemli internet kullanımını yordamadığ1 görülmüştür. Tsai ve diğerleri (2009) tarafından yapılan çalışmada da nörotik kişilik özelliği, internet bağımlılığ1 ile pozitif ilişkili bulunmuştur.

Yapılan çalışmalar incelendiğinde çalışmalar arasında farklılıkların olduğu görülmektedir. Yurt içinde yapılan çalışmaların sınırlı olması nedeniyle böyle bir çalışmaya gerek duyulmuştur.

\section{Yöntem}

\section{Araştırma Modeli}

Araştırma, tarama modeline uygun olarak planlanmış ve gerçekleştirilmiştir. Tarama modelinde; ilgilenilen olay, grup gibi birim ve duruma ait değişkenler, ayrı ayrı betimlenmeye çalışlır. $\mathrm{Bu}$ modelde, anlık durum saptamaları belirlenebilmektedir (Karasar, 2006 ). 
Taş, İ. \& Ayas, T. (2015). Lise öğrencilerinin internet bağımllık düzeyinin kişilik özellikleri ile ilişkisi. International Journal of Human Sciences, 12(2), 150-162. doi:10.14687/ijhs.v12i2.3279

\section{Katılımc1lar}

Araştırmanın katılımcıları İstanbul ili merkezinde yer alan farklı liselerde öğrenim gören 927 öğrenciden oluşmaktadır. Katılımcıların 252’si (\%27.2) dokuzuncu sınıf öğrencilerinden, 299’u (\%32.2) onuncu sınıf öğrencilerinden, 274’ü (\%29.5) on birinci sinıf öğrencilerinden ve 102'si (\%11) on ikinci sınıf öğrencilerinden oluşmuştur. Katıllımcılardan 440’1 (\%47.5) bayan, 487'si (\%52.5) erkektir. Öğrenciler 14 ile 18 yaş arasında olup, çoğunluğu 16 yaşındadır.

\section{Veri Toplama Araçları}

\section{Kişilik Özellikleri Ölçeği}

Ölçek, Gosling, Rentfrow ve Swann (2003) tarafindan geliştirilmiştir, Günel (2010) tarafindan Türkçeye uyarlanmıştır. Kişilik özellikleri ölçeğine uygulanan faktör analizi sonucunda 5 faktör elde edilmiştir. Bu faktörler beş faktör kişilik modelinde belirtilen faktörlerle aynı olarak adlandırılmıştır (dışadönüklük, yumuşak başl11ı, öz denetim, duygusal denge ve gelişime açılık). Ölçeğin Cronbach Alfa katsayısı .85 olarak hesaplanmıştır.

\section{İnternet Bağımlılığı Ölçeği}

Araştırmada öğrencilerin internet bağımlılı̆̆ Ayas, Balta ve Horzum(2011) tarafindan geliştirilen “Ergenler İçin Bilgisayar Bağımlıllğı Ölçeğı” kullanılarak ölçülmüştür. İnternet bağımlllı̆̆1 testi ile ilgili görüşler için 5’li Likert tipi dereceleme kullanılmıştır. Bu dereceleme "Her zaman (5), Çoğu Zaman (4), Sıklıkla (3), Ara Sıra (2) ve Nadiren (1)” şeklinde oluşturulmuştur.

\section{Ölçeğin Geçerlilik Çalışmaları}

Ölçek 54 madde iki faktörden oluşmaktadır. Bu faktörlerden birincisinde toplam 28 madde yer almaktadır. Bu maddelerin faktördeki yük değerleri .512 ile .795 arasında değişmektedir. Ölçeğin toplam varyansının \%29.49'unu açıklayan bu faktör “internet kullanım bağımlılı̆̆ı" olarak adlandırılmıştır. Ölçekte yer alan ikinci faktör ise, toplam 26 maddeden oluşmaktadır. $\mathrm{Bu}$ maddelerin ikinci faktördeki yük değerleri .424 ile .788 arasında değişmektedir. Ölçeğin toplam varyansının \%19.13'ünü açıklayan bu faktör "bilgisayar oyun bağımlılı̆̆ı" olarak isimlendirilmiştir.

\section{Ölçeğin Güvenilirlik Çalışmaları}

Ölçeğin güvenilirliği için Cronbach Alfa iç tutarlılık katsayısı hesaplanmıştır. İç tutarlılık testi sonuçlarında internet kullanım bağımlıllğı olarak adlandırılan alt faktörün iç tutarlılık katsayısı .96 ve bilgisayar oyun bağımlılı̆̆1 olarak adlandırılan alt faktörün iç tutarlılık katsayısı ise 95 olarak bulunmuştur. Ölçeğin 54 maddeden oluşan toplam iç tutarllık katsayısı .95 olarak bulunmuştur. 

of Human Sciences, 12(2), 150-162. doi:10.14687/ijhs.v12i2.3279

\section{Bulgular}

Kişilik özelliklerine gore internet bağımlılığının yordanmasına ilişklin regresyon analiz sonuçları tablo 1' de yer almaktadır.

Tablo.1 İnternet Bağımllhĭgn Yordanmasma İliskkin Cokelu Regresyon Analizi Sonuclar

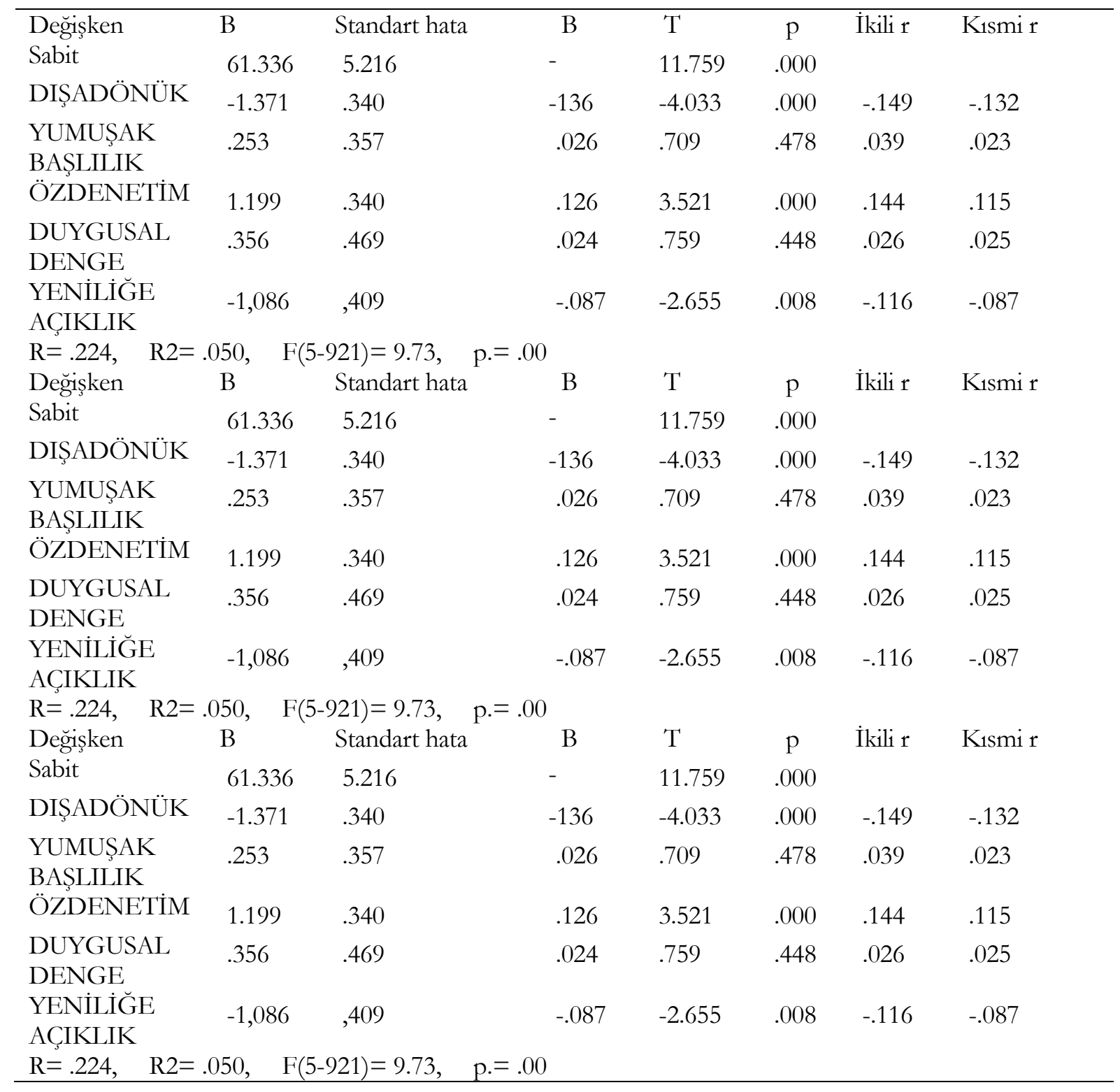

Tablo 1'de yer alan analiz sonuçlarında öncelikle internet bağımlllı̆̆ değişkeni ile kişilik özellikleri değişkenini yordayacak değişkenler arasındaki ikili ve kısmi korelasyon sonuçları incelenecektir. İnternet bağımlılı̆̆ ile Dışadönüklük arasında negatif ve düşük düzeyde bir ikili ilişki ( $\mathrm{r}=$-.15) olduğu ancak diğer değisskenler kontrol edildiğinde iki değişken arasındaki kısmi korelasyonun negatif ve düşük bir ilişki ( $r=$-.13) olarak hesaplandığ1 görülmektedir. İnternet Bağımlılığ1 ile 
Taş, İ. \& Ayas, T. (2015). Lise öğrencilerinin internet bağımlllık düzeyinin kişilik özellikleri ile ilişkisi. International Journal of Human Sciences, 12(2), 150-162. doi:10.14687/ijhs.v12i2.3279

Yumuşak Başl1lık arasında pozitif ve düşük düzeyde bir ikili ilişki $(r=.04)$ olduğu ancak diğer değişkenler kontrol edildiğinde iki değişken arasındaki kısmi korelasyonun pozitif ve düşük bir ilişki $(\mathrm{r}=.02)$ olarak hesaplandığı görülmektedir. İnternet Bağımlılı̆̆1 ile Özdenetim arasında pozitif ve düşük düzeyde bir ikili ilişki ( $(r=.14)$ olduğu ancak diğer değişkenler kontrol edildiğinde iki değişken arasındaki kısmi korelasyonun pozitif ve düşük bir ilişki ( $\mathrm{r}=$.12) olarak hesaplandığı görülmektedir. İnternet Bağımlılı̆̆ı ile Duygusal Denge arasında pozitif ve düşük düzeyde bir ikili ilişki $(\mathrm{r}=.03)$ olduğu ancak diğer değişkenler kontrol edildiğinde iki değişken arasındaki kısmi korelasyonun pozitif ve düşük bir ilişki ( $\mathrm{r}=.03)$ olarak hesaplandığı görülmektedir. İnternet bağımlıllğı ile Yeniliğe Açılık arasında negatif ve düşük düzeyde bir ikili ilişki $(r=-.12)$ olduğu ancak diğer değişkenler kontrol edildiğinde iki değişken arasındaki kısmi korelasyonun negatif ve düşük bir ilişki ( $\mathrm{r}=$-.09) olarak hesaplandığı görülmektedir.

Kişilik özellikleri değişkenleri birlikte ele alındığında internet bağımlılığı ile pozitif, düşük düzeyde ve anlamlı bir ilişki olduğu görülmektedir $(\mathrm{R}=.22, \mathrm{p}<.01)$. Kişilik özellikleri birlikte ele alındığında internet bağımlılı̆̆1 toplam varyansının \%05’ini açıklamaktadır. Standardize edilmiş regresyon kaysayısına ( $\beta$ ) göre yordayıcı değişkenlerin internet bağımlılı̆̆ üzerindeki göreli önem sırası; dışadönüklük, özdenetim, yeniliğe açıklık, yumuşak başlılık ve duygusal denge şeklindedir.

Regresyon katsayılarının anlamlllığına ilişkin t-testi sonuçları incelendiğinde ise Dışadönüklük değişkeninin internet bağımlılı̆̆ı üzerinde anlamlı bir yordayıcı olduğu görülmektedir.

Regresyon analizi sonuçlarına göre internet bağımlılı̆̆ı ve kişilik özelliklerine yönelik regresyon eşitliği;

INTTERNET BAĞIMLILIĞI= + 61.33 -.09 DIŞADÖNÜKLÜK +.81 YUMUŞAK BAŞLILIK .18 ÖZDENETİM - .18 DUYGUSAL DENGE +.03 YENİLİĞE AÇIKLIK olarak bulunmuştur

\section{Tartışma Ve Sonuç}

Teknolojik çağın getirmiş olduğu en önemli gelişmelerden biri haline gelen internet, yaygınlaşmasına bağlı olarak bireyler tarafindan değişik amaçlar doğrultusunda yaygın olarak kullanılır hale gelmiştir. Yaygın olarak kullanılan bu teknoloji bireyler üzerinde oluşturmuş olduğu etkiler nedeniyle psikoloji literatürüne de girerek farklı çalışmaların yapılmasına neden olmuştur. Özellikle internetin yaygın kullanılması sonucu bireylerin fiziksel, sosyal, ailevi ve eğitim hayatlarında oluşturduğu olumsuz etkilerin artmasıyla birlikte ruh sağlığı alanında çalışan bireylerin internete yönelik çalışmalarının son yıllarda daha da arttı̆ı̆ görülmektedir. 
Taş, İ. \& Ayas, T. (2015). Lise öğrencilerinin internet bağımlılık düzeyinin kişilik özellikleri ile ilişkisi. International Journal of Human Sciences, 12(2), 150-162. doi:10.14687/ijhs.v12i2.3279

İnternet bağımlılık düzeyinin kişilik özellikleriyle ilişkisini incelemek amacıyla yapılan bu çalışmada internet bağımlılık düzeyinin dışa dönüklük kişilik özelliğiyle negatif düşük düzeyde bir ilişkisinin olduğu görülmektedir. Bu bulgu (Çelik, Atak ve Başal, 2012; Dalbudak ve Evren, 2013; Landers ve Lounsbury, 2006; Morsünbül, 2014; Servidio, 2014; Volmer ve dĭ̆. 2014) bulgularryla tutarlllik göstermektedir. Özkan'ın (2013) bulgusundan farkl1lık göstermektedir. Dışadönüklük kişilik boyutu bireyin daha çok sosyallik ve cana yakınlık düzeyini temsil eder. Dışadönük olan kimseler dış dünyaya karşı daha çok enerjik bir yaklaşım içerisinde olup genel olarak sosyal, aktif, girişken ve pozitif duygularla ifade edilebilirler. İçedönük kimseler ise genellikle içekapanık, çekingen, daha az aktif ve daha az pozitif duygular sergileme eğilimindedirler (Glass ve diğerleri, 2013). Dışadönük bireylerin kendilerini daha iyi ifade edebilmeleri ve kolaylıkla iletişim kurabilmeleri nedeniyle internette daha az zaman harcadıkları düşünülebilir. Ancak içe dönük yalnız ve utangaç olan bireyler daha fazla internette zaman harcadıkları için daha fazla internet bağımlısı olabilmektedirler (Ayas, 2012; Ayas, ve Horzum, 2013). Dişadönük bireylerin sosyal ilişki kurma ve bu ilişkileri yürütebilme konusunda başarılı olabilecekleri düşünüldüğünde, interneti bir iletişim aracı olarak içedönük bireylerden daha az kullandıkları düşünülebilir. İçedönük bireylerin sosyal ilişki kurma konusunda sorunlar yayabilecekleri ve bu bireylerin bundan dolayı interneti sosyalleşme aracı, duygu ve düşüncelerini diğerlerine aktarabildikleri bir araç olarak kullanabilecekleri düşünüldügünde, içedönük bireylerin dışadönük bireylerden daha fazla internet bağımlısı olma ihtimali olduğu söylenebilir.

Araştırmanın diğer bir bulgusu incelendiğinde özdenetim ile internet bağımllık düzeyi arasında pozitif ve düşük düzeyde bir ilişki olduğu görülmektedir. Bu bulgu Kuss ve arkadaşları (2013) tarafindan yapılan araştırmanın bulgularıyla tutarllık göstermektedir. Bulgu (Rahmani ve Lavasani, 2011; Durak Batıgün ve Kılıç, 2011) bulgulanından farklılık göstermektedir. Özdenetim kişilik özelliğine sahip bireylerin azimli, hırslı, başarı yönelimli oldukları düşünüldüğünde, bu kişilik özelliklerinin özellikle internet oyunlarında daha fazla zaman harcanmasına neden olduğu düşünülebilir. Bundan dolayı da internet bağımlılık düzeyleri daha yüksek olmuş olabilir.

Araştırmanın diğer bir bulgusunda yeniliğe açıklıkla internet bağımlılık düzeyi arasında düşük düzeyde negatif bir ilişki olduğu görülmektedir. Yeniliğe açıklık, beş faktör kişilik yapısı içinde bilişsel yönü en fazla olan özelliktir. Bu açıdan yüksek seviyede gelişime açık olan bireyler, hayal kuran, macerac1, orijinal, yaratıc1, merakl1, kendi düşünce ve duygularına yönelen; düşük seviyedekiler ise geleneksel, tutucu, ilgisiz olarak nitelendirilmektedirler (Costa ve McCrae, 1995). Yeniliğe açık olan bireyler maceracı ve meraklı olmaları nedeniyle sürekli farklı bir yenilik peşinde gezinmektedirler. Bu nedenle internette de sürekli farklı sayfalarda gezine bilmekteler buna bağlı 
Taş, İ. \& Ayas, T. (2015). Lise öğrencilerinin internet bağımlılık düzeyinin kişilik özellikleri ile ilişkisi. International Journal of Human Sciences, 12(2), 150-162. doi:10.14687/ijhs.v12i2.3279

olarak da internetin dışındaki farklı etkinliklerde de vakit harcayabildikleri için internet bağımlılık düzeyinde negatif bir ilişki olmuş olabilir.

İnternet bağımlılığında bireylerin kişilik yapılarının önemli bir değişken olduğu yapılan bu araştırmayla görülmektedir. Araştırmadan elde edilen bulgular değerlendirildiğinde internet bağımlılığını önlemeye yönelik planlanacak çalışmalarda bireylerin kişilik özellikleri dikkate alınarak program hazırlanmasının gerektiği görülmektedir.

\section{Kaynakça}

Altınköprü, T. (1980). Şahsiyet Analizi. İstanbul: Altınköprü Yayınları.

Atkinson, R.L., Atkinson, R.C. ve Hilgard, E.R. (1995). Psikolojiye Giriş. İstanbul: Sosyal Yayınlar.

Ayas, T. ve Horzum, M.B. (2013) Relation Between Depression, Loneliness, Self-Esteem And Internet Addiction. Education. 133,3, 283-290.

Ayas, T. (2012). The Relationship Between internet and Computer Game Addiction Level And Shyness Among High School Students. Educational Sciences: Theory And Practice. 2. 632636.

Ayas, T, Balta, Ç, Ö. ve Horzum, M.B (2011). Ergenler İçin Bilgisayar Bağımlılığı Ölçeği. Kastamonu Ë̆itim Dergisi. 19(2),339-448.

Beranuy, M., Oberst, U., Carbonell, X. ve Chamarro. (2009). Problematic Internet And Mobile Phone Use And Clinical Symptoms in College Students: The Role Of Emotional Intelligence. Computers in Human Behavior. 25. 1182-1187.

Burger, J.M. (2006). Kişilik. İstanbul: Kaknüs Yayınları.

Cao, F. ve Su.L. (2006). Internet Addiction Among Chinese Adolescents: Prevalence And Psychological Features. Child: care, health and development. 33, 3, 275-281.

Chew, K.H.P. ve Dillon, D.B. (2014). Statistics Anxiety And The Big Five Personality Factors. Procedia - Social And Behavioral Sciences. 112. 1177 - 1186.

Chou,C., Condron, L.A. ve Belland, J.C. (2005). Review of the Research on Internet Addiction. Educational Psychology Review. 17. 4. 363-388.

Costa, P. T., ve McCrae, R. R. (1995). Domains and Facets: Hierarchical Personality Assessment Using The Revised NEO Personality Inventory. Journal of Personality Assessment. 64 (1), 21-50.

Çelik, S., Atak, H.ve Başal, A. (2012). Predictive Role Of Personality Traits on Internet Addiction. Turkish Online Journal of Distance Education-TOJDE. 13. 4. 1. 10-24.

Dalbudak, E. ve Evren, C. (2013). The relationship of Internet addiction severity with Attention Deficit Hyperactivity Disorder symptoms in Turkish University students; impact of personality traits, depression and anxiety. Comprehensive Psychiatry. $\mathrm{xx} . \mathrm{xxx}-\mathrm{xxx}$.

Durak Batıgün, A ve Kılıç, N. (2011). İnternet Bağımlllı̆ı ile Kişilik Özellikleri, Sosyal Destek, Psikolojik Belirtiler ve Bazı Sosyo-Demografik Değisskenler Arasındaki İlişkiler. Türk Psikoloji Dergisi. 26(67),1-10. 
Taş, İ. \& Ayas, T. (2015). Lise öğrencilerinin internet bağımlılık düzeyinin kişilik özellikleri ile ilişkisi. International Journal of Human Sciences, 12(2), 150-162. doi:10.14687/ijhs.v12i2.3279

Glass, R., Prichard, J., Lafortune, A., and Schwab, N. (2013). The Influence Of Personality And Facebook Use on Student Academic Performance. Issues in Information Systems. 14(2), 119126.

Haddadain, F., Abedin, A. Ve Monirpoor,N. (2010). Appraisal Of Personality, Family Structure And Gender in Predicting Problematic Use Of Internet. Procedia Social and Behavioral Sciences. 5. 850-854.

Hamburger, Y.A. ve Ben-Artzi, E. (2000). The Relationship Between Extraversion and Neuroticism and The Different Uses of The Internet. Computer in Human Behavior. 16. 441449.

Haskan, Ö. (2013). Internet Kullammuyla İlgili Değişkenlerin Cinsiyet, Kişilike Özellikleri, Yaşam Doyumu Ve Bağlanma Stilleri Açısından Incelenmesi. Yayınlanmamış Yüksek Lisans Tezi. Ankara Üniversitesi. Sosyal Bilimler Enstitüsü. Ankara.

Kalkan, M. Ve Kaygusuz, C. (2013). Internet Bağımlılğ̆ı. Ankara: Anı Yayınc1lı

Karasar, N. (2006). Bilimsel Araștırma Yöntemi. Ankara: Nobel Yayıncılık.

Ko, C.H., Yen, J.Y., Chen, C.S., Yeh, Y.C. ve Yen, C.F. (2009). Predictive Values Of Psychiatric Symptoms For Internet Addiction in Adolescents. Arch Pediatr Adolesc Med. 163. 10. 937943.

Ko, C.H., Yen, J.Y., Yen, C.F., Chen, C.S. Ve Chen, C.C. (2012). The Association Between Internet Addiction And Psychiatric Disorder: A Review of The Literatüre. European Psychiatry. 27. 1 8.

Köknel, Ö. (1982). Kaygıdan Mutluluğa Kişilik. Altın Kitaplar Yayınevi.

Köse, D., Çınar, N. Ve Akduran, F. (2012). Hemşirelik Öğrencilerinde İnternet Bağımlıllğının Kişilik Özellikleri Ve Zaman Yönetimi İle İlişkisi. Sakarya üniversitesi Fen Bilimleri Enstitüsü Dergisi. 16.3. 227-233.

Kuss, D.J., Shorter, G.W., Rooij, A.J.V , Mheen, D.V. ve Griffiths. (2014). The Internet Addiction Components Model And Personality: Establishing Construct Validity Via A Nomological Network. Computers in Human Behavior. 39. 312-321.

Kuss, D.J., Griffiths, M.D ve Binder, J.F. (2013). Internet Addiction in Students: Prevalence And Risk Factors. Computers in Human Behavior. 29. 959-966.

Kuss, D.j., , Rooij, A.J.V, Shorter, G.W., Griffiths, M.D., Mheen, D.V., (2013). Internet Addiction in Adolescents: Prevalence And Risk Factors. Computers in Human Behavior. 29 1987-1996.

Landers, R.N. ve Lounsbury, J.W. (2006). An investigation Of Big Five And Narrow Personality Traits in Relation to Internet Usage. Computer in Human Behavior. 22, 283-293.

Morsünbül, Ü. (2014). İnternet Bağımlılı̆̆ının Bağlanma Stilleri, Kişilik Özellikleri, Yalnızlık Ve Yaşam Doyumu İle İlişkisi. International Journal of Human Sciences. 11.1 357-372.

Özkan, Ö. (2013). İnternet Kullanımylla İlgili Değisskenlerin Cinsiyet, Kişilik Özellikleri, Yaşam Doyumu $V e$ Bağlanma Stilleri Açısından Incelenmesi. Yayınlanmamıs Yüksek Lisans Tezi. Ankara Üniversitesi. Sosyal Bilimler Enstitüsü. Ankara.

Plotnik, R. (2009). Psikolojize Giriș. İstanbul: Kaknüs Yayınları.

Rahmani, S. Ve Lavasani, M.G. (2011). The Relationship Between Internet Dependency With Sensation Seeking And Personality. Procedia - Social And Behavioral Sciences 30. 272 - 277. 
Taş, İ. \& Ayas, T. (2015). Lise öğrencilerinin internet bağımlılık düzeyinin kişilik özellikleri ile ilişkisi. International Journal of Human Sciences, 12(2), 150-162. doi:10.14687/ijhs.v12i2.3279

Shapira, N.A., Lessing, M.C., Goldsmith, T.D., Szabo, S.T., Lazoritz, M., Gold, M.S. ve Stein, D.J. (2003). Problematic İnternet Use: Proposed Classification And Diagnostic Criteria. Depression And Anxiety. 17. 207-216.

Shaw, M. Ve Black D.W. (2008).Internet Addiction. CNS Drugs. 22 (5). 353-365.

Servidio, R. (2014). Exploring The Effects Of Demographic Factors, Internet Usage And Personality Traits On Internet Addiction in A Sample Of Italian University Students. Computers in Human Behavior. 35. 85-92.

Taş, İ., Eker, H. ve Anlı, G. (2014). Ortaöğretim öğrencilerinin internet ve oyun bağımlılık düzeylerinin incelenmesi. Online Journal Of Technology Addiction \& Cyberbullying. 1 (2) . 37-57.

Tsai, H.F., Cheng, S.H., Yeh, T.L., Shih, C.C., Chen, K.C., Yang, Y.C ve Yang, Y.K. (2009). The Risk Factors Of Internet Addiction-A Survey Of University Freshmen. Psychiatry Research. 167. 294-299.

Wang, C.W., Ho, R.T.H., Chan, C.L.W ve Tse, S. (2015). Exploring Personality Characteristics Of Chinese Adolescents With Internet-Related Addictive Behaviors: Trait Differences For Gaming Addiction And Social Networking Addiction. Addictive Behaviors. 42. 32-35.

Vollmer, C Randler, C; Horzum, M.B; Ayas, T (2014) Computer Game Addiction in Adolescents and Its Relationship to Chronotype and Personality SAGE Open 1-9 DOI: $10.1177 / 2158244013518054$.

Yörükoğlu, A. (1986). Gençlik Çăğ. Ankara: Türkiye İş Bankası Kültür Yayınları.

\section{Extended English Abstract}

Personality concept is derived from the word "persona" which means mask in Latin that theatre players wear as appropriate to their roles in the theater (Köknel, 1982). Personality is multifaceted and is a complex structure. It incorporates various factors such as intelligence, emotion, will, excitement, temperament, biological structure, heredity, environment and socio-economic factors (Altınköprü, 1980). Psychologists could not compromise on personality concept. However, as a common expression of all approaches, it can be defined as consistent behavior patterns and thought styles which determines the adaptation of the invidual to environment (Atkinson, Atkinson ve Hilgard, 1995).

In the modern world, the use of computers and access to the internet are widespread. People from all walks of life can spend beneficial hours by using the computers or accessing the internet (Shaw ve Black, 2008). In recent years, the internet emerges as the most important academic and entertainment tool both for adolescents and adults.

The subject of addiction to information and communication technologies was discussed widely in the last few years. In this manner, there is also a considerable increase of studies in scientific literature about the impact of new technologies on the mental health. Because, the use of technology may lead to psychological distress or disorders (Beranuy, Oberst, Carbonell ve Chamarro, 2009). The interest of technology dependence find its roots in the beginning of the 1990s. Firstly, researchers explored the influence of the television (Kubey ve Csikszenmihalyi, 2002. Akt. Shapira, Lessing, Goldsmith, Szabo, Lazoritz, Gold ve Stein, 2003).

The data of this study was obtained from 927 students studying at different high schools. 252 $(27.2 \%)$ of them were $9^{\text {th }}$ class, $299(32.2 \%)$ were from $10^{\text {th }}$ class, $274(\% 29.5)$ were from $11^{\text {th }}$ class while $102(\% 11)$ of the students were studying at the $12^{\text {th }}$ class. The female / male distribution of the study was $440(\% 47.5)$ to $487(\% 52.5)$, respectively. The participants aged between 14 to 18 , while the majority were 16 years old. 
Taş, İ. \& Ayas, T. (2015). Lise öğrencilerinin internet bağımllık düzeyinin kişilik özellikleri ile ilişkisi. International Journal of Human Sciences, 12(2), 150-162. doi:10.14687/ijhs.v12i2.3279

The research was planned and carried out in accordance with the survey model. In the survey model, the variables like the unit and event of interest and the group are aimed to be described separately. In this model, instant state determinations can be specified (Karasar, 2006 ).

Personality traits scale was developed by Gosling, Rentfrow, and Swann (2003) and adapted to Turkish by Gunel (2010). As a result of factor analysis, five factors were obtained. These factors have been named as the same provided in the five factor personality model (extraversion, openness, conscientiousness, emotional stability, and agreeableness). Cronbach Alpha coefficient of scale was calculated as .85 .

In the study, Computer Addiction Scale for adolescents, developed by Ayas, Balta ve Horzum(2011), has been used to measure internet addiction. 5- point likert scale ranging scale has been used for the consideration of internet addiction. The ranging has been structured as 1 ("rarely"), 2 ("sometimes"), 3 ("often"), 4 ("usually") and 5 ("always").

The scale consists of 54 items and two factors. The first of these factors comprise of 28 items. These items' factor load values vary between .512 and .795 . This factor that explains $29.49 \%$ of the total variance of the scale has been named as "internet addiction scale". The latter of these factors consists of 26 items. These items factor load values change between .424 and .788 explaining $19.13 \%$ of the total variance of the scale and named as "computer game addiction".

Cronbach alfa internal consistency coefficient was calculated for the reliability of the scale. Internal consistency coefficient of the internet addiction scale was found as .96 while the coefficient of the computer game addiction was found as .95 . The total internal consistency coefficient of the scale comprising 54 items was evaluated as .95.

Results indicated that there is a low level negative relationship ( $r=-.15)$ between internet addiction and extraversion. On the other hand, when other variables were controlled, it is obtained that the partial correlation between two variables was calculated as negative low level $(\mathrm{r}=.13)$. There was a low level positive $(r=.04)$ relationship between internet addiction and agreeableness, however, when other variables were controlled, it is found that the partial correlation between two variables was calculated as low level positive $(r=.02)$. There was a low level positive relationship $(r=.14)$ between internet addiction and conscientiousness, while the partial correlation between two variables was calculated as low level positive $(r=.12)$ when other variables were controlled. There was a low level positive relationship $(r=.03)$ between internet addiction and emotional stability, again when other variables were controlled, it can be deduced that the partial correlation between two variables was calculated as low level positive $(r=.03)$. There was a low level negative relationship $(\mathrm{r}=.12)$ between internet addiction and openness, but when other variables were controlled, it can be realized that the partial correlation between two variables was calculated as low level negative $(r=.09)$. When the variables of personality traits are considered as whole, it can be observed that a low level and positive significant relationship $(\mathrm{R}=.22, \mathrm{p}<.01)$ reveals between internet addiction and personality traits. For the same situation, this explains $05 \%$ of the total variance of internet addiction. According to the standardized regression coefficient $(\beta)$, the order of the relative importance of predictor variables on internet addiction are extraversion, conscientiousness, openness, agreeableness and emotional stability.

When t-test results for the significance of regression coefficients were examined, it was observed that extraversion is a significant predictor of internet addiction.

In this study, it can be noticed that personality traits are significant variables for internet addiction. When the findings from the research are evaluated, it can be concluded that the personality traits of the individuals are to be taken into account when preparing a program to prevent internet addiction. 